\title{
Buck-Boost-Full-Bridge Inverter for All-Metals Induction Heating Cookers
}

\author{
Hiroyuki Shoji ${ }^{*, * a a)}$ Member, \\ Junpei Uruno* \\ Member \\ Masayuki Isogai ${ }^{* * *}$ Non-member, \\ Takeshi Yanagidaira** Member
}

(Manuscript received July 31, 2015, revised Jan. 22, 2016)

\begin{abstract}
In this paper, we present a buck-boost-full-bridge (BBFB) inverter that is a novel circuit topology developed for all-metals induction heating cookers. A power device of a full bridge inverter serves as a part of the H-bridge PAM (Pulse Amplitude Modulation) converter, thus reducing the number of power devices. In iron pan heating, it consists of a buck converter stage and a full bridge inverter stage with a boost function. On the other hand, in aluminum pan heating, it completely becomes independent of the H-bridge PAM converter stage and a single-ended push-pull (SEPP) inverter stage. For iron pan heating, the power conversion efficiency showed an approximately flat characteristic in a wide power range.
\end{abstract}

Keywords: high-frequency inverter, induction heating, power factor correction, H-bridge

\section{Introduction}

In recent years, global warming, environmental pollution, and solution of the energy problem have become major problems for mankind. For that reason, the development of power generation systems that use clean energy and the development of highly efficient, low-power-consumption equipment have become essential requirements. In the fields of home electronics and consumer appliances, there has been vigorous progress in the commercialization of products that use power electronics that are equipped with inverters that save energy through higher efficiency. Technology for achieving higher efficiency and lower noise includes soft switching, which reduces switching loss by zero-voltage switching (ZVS) or zero-current switching (ZCS). That technology has been progressing towards practical application in home electronics and consumer appliances such as electromagnetic cookers and lighting systems in which high frequencies are generated by series resonance circuits ${ }^{(1)(2)}$.

The current resonance inverters that are used in series resonance circuits can achieve soft switching simply by operating on current that has a phase that is delayed relative to the inverter output voltage. For power control, pulse frequency modulation (PFM) for operating in a frequency band higher than the resonance frequency is generally used. Nevertheless, in electromagnetic cooking appliances that have multiple heating elements, such as induction heating cookers, the

a) Correspondence to: Hiroyuki Shoji. E-mail: hiroyuki.shoji.aq @ hitachi.com

* Research \& Development Group, Hitachi, Ltd.

7-1-1, Omika-cho, Hitachi-shi, Ibaraki 319-1292, Japan

** Ibaraki University

4-12-1, Nakanarusawa-cho, Hitachi-shi, Ibaraki 316-8511, Japan

${ }^{* * *}$ Hitachi Appliances, Inc.

1-1-1, Higashitaga-cho 1-chome, Hitachi-shi, Ibaraki 3168502, Japan frequency difference of adjacent heating elements can generate an audible interference sound ${ }^{(3)-(8)}$. Also, basic method of converting to high-frequency power by rectification of commercial AC voltage and inputting the uneven DC link voltage to an inverter can heat cookware that has high resistivity such as pans made of iron or magnetic stainless steel, but it cannot easily heat cookware made of non-magnetic, low resistivity materials such as copper or aluminum. About one-third of the cookware used in homes is made of aluminum, so a means of heating cookware made of any metal, including aluminum, is important.

The heating power in induction heating is proportional to the square of the surface resistance of the heated object and the magnetomotive force, raising the frequency of the eddy current flowing in the cookware to increase the surface resistance together with increasing the number of windings and the current of the work coil to attain a large magnetomotive force is an effective approach for heating cookware made of non-magnetic materials such as copper and aluminum. Increasing the frequency and number of windings makes power control by PFM difficult because of the increase in the quality factor $(\mathrm{Q})$ of the series resonance circuit and the increase in the sharpness of change near the resonance frequency in the frequency characteristic. Another problem is the noise that is produced when a large oscillating magnetic field couples with cookware made of aluminum or other lightweight material. To suppress changes in the DC link voltage applied to the inverter, it is necessary to suppress oscillation of the current flowing in the work coil. Also, a converter that has a power factor correction function in the first stage of the inverter is needed, because a power factor correction circuit for input high-frequency current regulation of the commercial AC power is required.

Thus, many problems must be overcome to achieve an all-metals induction heating cooker that can be used with cookware made of metals that have different characteristics, 


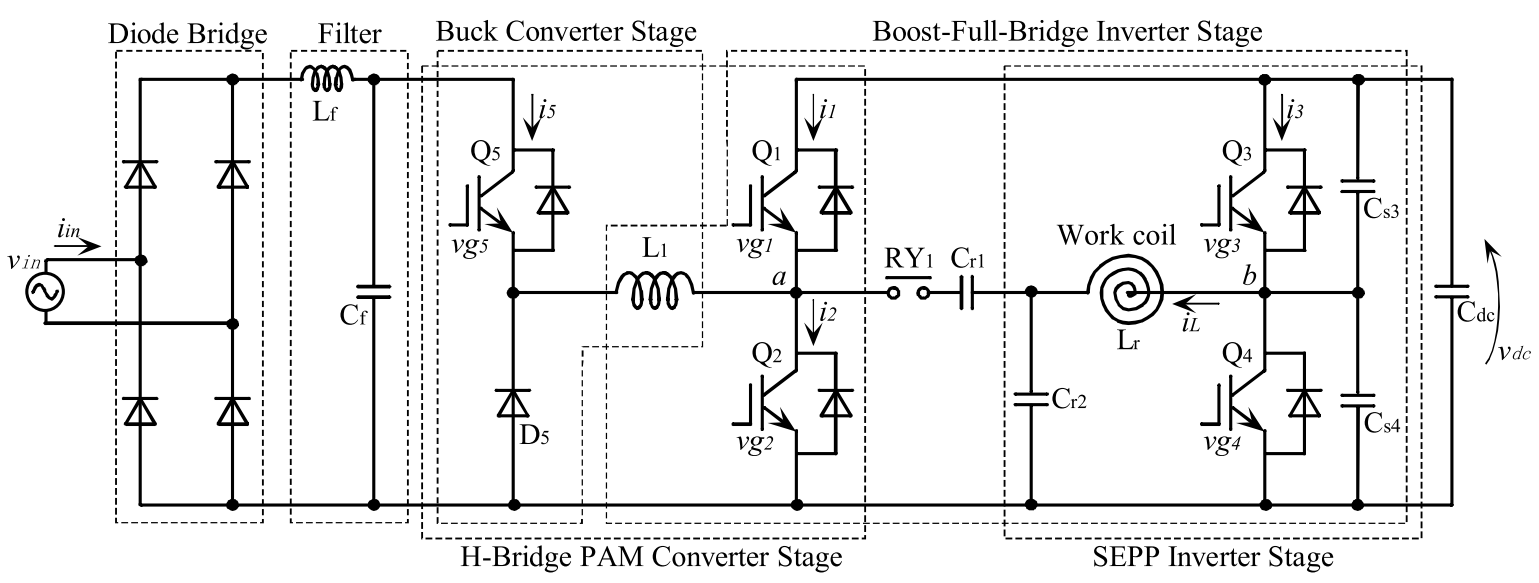

Fig. 1. Buck-Boost-Full-Bridge inverter

ranging from iron and magnetic stainless steel to aluminum and copper. As an approach to solving those problems, a circuit in which a B-HB (Boost-Half Bridge) triplex resonance inverter is connected to the later stage of a passive filter that consists of a high-inductance reactor and capacitor has been developed ${ }^{(9)}$. In that approach, the unit operates in triplex mode with the resonant frequency three times higher than the inverter switching frequency when heating an aluminum pan. During the time the switch is conductive, resonance of one cycle or more is obtained, and the current frequency of the work coil can be made high, even if the switching frequency is low. As a result, the increase in switching loss can be suppressed, but the input current waveform is distorted by the passive filter. We have taken a different approach in proposing an all-metals induction heating system in which the number of windings of the work coil is switched according to the type of cookware material, a PFC function and a PAM (Pulse $\underline{\text { Amplitude }}$ Modulation) converter that has a buck-boost function are placed on the primary side of the inverter, and the PAM converter voltage is switched to drive the inverter when the heated material is copper or aluminum $^{(10)(11)}$. After that, We proposed an induction heating system in which the number of work coil windings is fixed and the inverter is switched to a full-bridge scheme or a modified half-bridge SEPP ( Single Ended Push Pull) scheme according to the type of material of the heated object and the heating power setting ${ }^{(12)}$. Also, an H-bridge PAM converter that has a PFC function was proposed to eliminate the chopper choke coil and increase efficiency in the converter ${ }^{(13)}$. To further eliminate a power device, we propose here a buckboost-full-bridge inverter, which we refer to as the BBFB inverter. The BBFB inverter is used as both an H-bridge PAM converter and part of a full-bridge inverter ${ }^{(14)}$. In this paper, we describe the circuit configuration and power control method of the proposed BBFB inverter and present experimental results.

\section{New BBFB Inverter}

2.1 Circuit Configuration The circuit configuration of the BBFB inverter is shown in Fig. 1. The proposed inverter consists of a boost full-bridge inverter that comprises the main switching devices $\mathrm{Q}_{1}$ to $\mathrm{Q}_{4}$, the inductive heating work coil $\mathrm{L}_{\mathrm{r}}$, resonant capacitors $\mathrm{C}_{\mathrm{r} 1}$ and $\mathrm{C}_{\mathrm{r} 2}$, relay $\mathrm{RY}_{1}$,

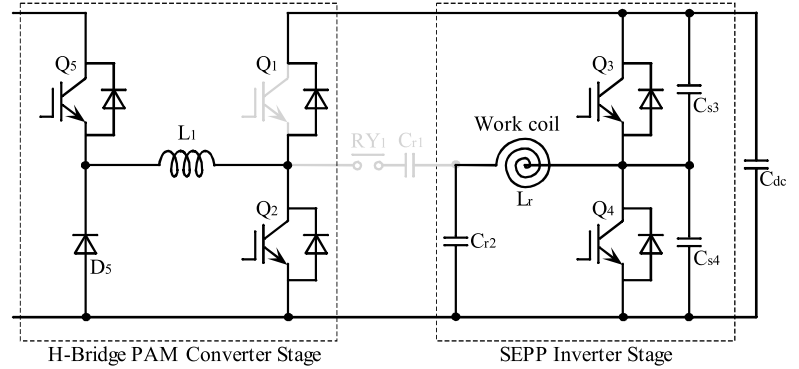

(a) When the pan is heated low-resistivity materials

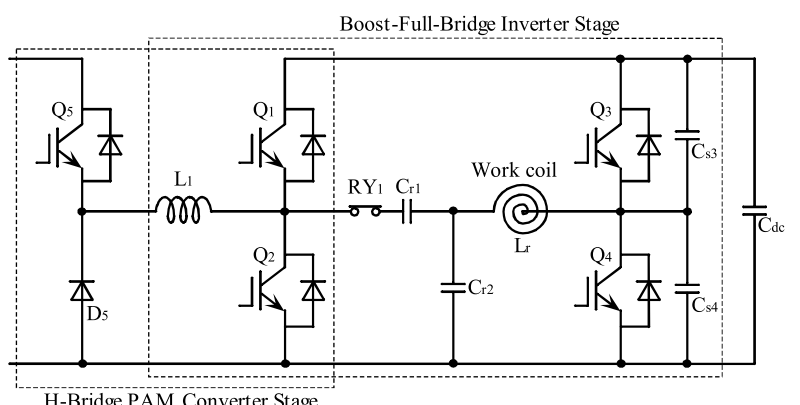

(b) When the pan is heated high-resistivity materials

Fig. 2. Circuit to transform by the materials of the pan

and a buck converter that comprises chopper inductor $\mathrm{L}_{1}$, the first-stage switching device $\mathrm{Q}_{5}$, and freewheeling diode $\mathrm{D}_{5}$. The switching devices $\mathrm{Q}_{1}$ to $\mathrm{Q}_{5}$ use IGBT and each is equipped with an anti-parallel diode. $\mathrm{Q}_{3}$ and $\mathrm{Q}_{4}$, which constitute the right leg of the inverter, have parallel lossless snubber capacitors $\mathrm{C}_{\mathrm{s} 3}$ and $\mathrm{C}_{\mathrm{s} 4}$ for $\mathrm{ZVS}$.

For heating low-resistance aluminum cookware, relay $\mathrm{RY}_{1}$ is turned off to isolate resonant capacitor $\mathrm{C}_{\mathrm{r} 1}$ from switching devices $\mathrm{Q}_{1}$ and $\mathrm{Q}_{2}$, and work coil $\mathrm{L}_{\mathrm{r}}$ and resonant capacitor $\mathrm{C}_{\mathrm{r} 2}$ form a resonant load circuit so that the inverter operates by SEPP with $\mathrm{Q}_{3}$ and $\mathrm{Q}_{4}$ as the switching devices as shown in Fig. 2(a). The converter becomes an H-bridge PAM converter that comprises switching devices $\mathrm{Q}_{1}, \mathrm{Q}_{2}$, and $\mathrm{Q}_{5}$, freewheeling $\mathrm{D}_{5}$, and chopper reactor $\mathrm{L}_{1}$, and is entirely isolated from the inverter.

When heating high resistance steel, on the other hand, relay $\mathrm{RY}_{1}$ is in the conductive state, connecting resonant capacitor $\mathrm{C}_{\mathrm{r} 1}$ to switching devices $\mathrm{Q}_{1}$ and $\mathrm{Q}_{2}$, inverter and work coil $\mathrm{L}_{\mathrm{r}}$ and resonant capacitor $\mathrm{C}_{\mathrm{r} 1}$ form a resonance load circuit and the inverter operates by the full-bridge method as shown in 
Fig. 2(b). The resonance frequency can be made to be governed by $\mathrm{C}_{\mathrm{r} 1}$ by setting the capacitance of resonant capacitors $\mathrm{C}_{\mathrm{r} 1}$ and $\mathrm{C}_{\mathrm{r} 2}$ such that $\mathrm{C}_{\mathrm{r} 1} \gg \mathrm{C}_{\mathrm{r} 2}$. Chopper inductor $\mathrm{L}_{1}$ is connected at the connection point of switching devices $\mathrm{Q}_{1}$ and $\mathrm{Q}_{2}$, which are the left leg of the full-bridge inverter, and the inverter takes on the configuration of a boost full-bridge inverter that has a boost function.

Thus, the proposed method configures the H-bridge PAM converter and SEPP inverter for independent operation when heating low-resistivity aluminum cookware, and the configuration is switched to use both the H-bridge PAM converter and part of the power elements of the full-bridge inverter when heating high resistivity cookware.

2.2 Power Control Method The operation waveforms for heating low-resistivity aluminum cookware are shown in Fig. 3. Figure 3(a) shows the drive signals for switching devices $\mathrm{Q}_{2}$ and $\mathrm{Q}_{5}$ for one cycle of the commercial power supply. In the region where the rectified voltage of the commercial power input voltage $\left|v_{i n}\right|$ is higher than the DC link voltage $v_{d c}$, switching device $\mathrm{Q}_{5}$ serves as a buck element in performing the switching operation. In the region where the rectified grid input voltage $\left|v_{i n}\right|$ is lower than the DC link voltage $v_{d c}$, switching device $\mathrm{Q}_{5}$ is always on and switching device $\mathrm{Q}_{2}$ performs the switching operation as a boost element.

The driving signals for $\mathrm{Q}_{3}$ through $\mathrm{Q}_{4}$ and the voltage waveform applied to the resonant load circuit $\left(v_{b}\right)$ are shown in Fig. 3(b). By driving $\mathrm{Q}_{3}$ and $\mathrm{Q}_{4}$ in complementary fashion, the DC link voltage $\left(v_{d c}\right)$ and $0 \mathrm{~V}$ are alternately applied to the resonant load circuit. The on-time duties of $\mathrm{Q}_{3}$ and $\mathrm{Q}_{4}$ are set to constant values and deadtime is inserted so that the on states do not occur at the same time is omitted from the figure. For low-resistivity cookware, the frequency characteristic for which the $\mathrm{Q}$ value of the series resonance circuit is high changes sharply near the resonance frequency, so PFM power control is difficult. For that reason, the SEPP inverter is operated to track the resonance point, and the amplitude of

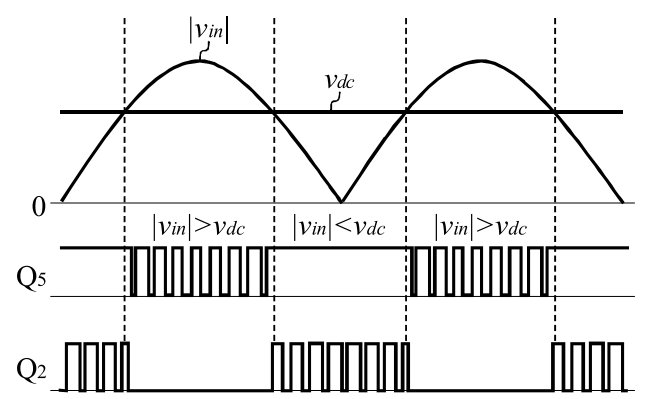

(a) H-bridge PAM Converter

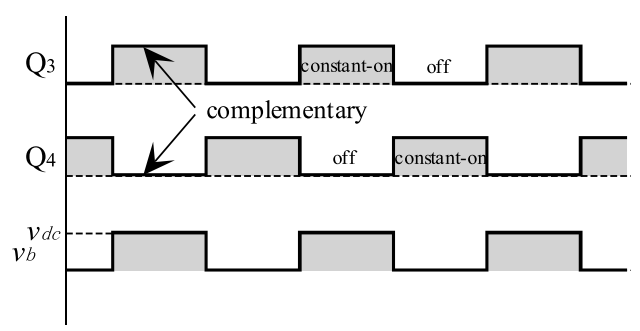

(b) SEPP Inverter

Fig. 3. Operating waveforms of BBFB inverter when the pan is heated low-resistivity materials the DC link voltage applied to the SEPP inverter is controlled by the H-bridge PAM converter, thus adjusting the power, which is to say that power control is performed by pulse amplitude modulation. As mentioned previously, when heating aluminum cookware, the large magnetic flux that links to the cookware produces a sound caused by vibration. To avert that problem, it is necessary to smooth the DC link voltage that is applied to the inverter to suppress the pulsation in the work coil current. The system proposed here can apply a smooth DC link voltage to the inverter by controlling the power factor of the commercial input current on which the H-bridge PAM converter operates and smoothing the output voltage. The H-bridge PAM converter controls the DC link voltage by the voltage feedback. Thus, ripple voltage included in the DC link voltage is reduced.

A feature of the proposed inverter in operation using switching device $\mathrm{Q}_{2}$ as both a boosting element of the $\mathrm{H}$ bridge PAM converter and as a full-bridge inverter element when heating high-resistivity iron cookware, as shown in Fig. 2(b). The operation waveforms for heating highresistivity iron cookware are shown in Fig. 4. Figure 4(a) shows the drive signals for switching devices $\mathrm{Q}_{2}$ and $\mathrm{Q}_{5}$ for one cycle of the commercial power supply. In the region where the rectified voltage of the commercial power input voltage $\left|v_{i n}\right|$ is higher than the DC link voltage $v_{d c}$, switching device $\mathrm{Q}_{5}$ serves as a buck element in performing the switching operation. In that case, it is possible to continue full-bridge inverter operation by continuing the switching operation of switching device $\mathrm{Q}_{2}$. In the region where the rectified grid input voltage $\left|v_{i n}\right|$ is lower than the DC link voltage $v_{d c}$, switching device $\mathrm{Q}_{5}$ is always on and switching device $\mathrm{Q}_{2}$ performs the switching operation as a boost element and inverter element.

The driving signals of switching devices $Q_{1}$ to $Q_{5}$ and the full-bridge inverter output voltage $v_{a b}$ are shown in Fig. 4(b) for $\left|v_{i n}\right|>v_{d c}$ and in Fig. 4(c) for $\left|v_{i n}\right|<v_{d c}$. $\mathrm{Q}_{1}$ and $\mathrm{Q}_{2}$, and $\mathrm{Q}_{3}$ and $\mathrm{Q}_{4}$ respectively operate in complementary fashion, and the on-duty of $\mathrm{Q}_{3}$ and $\mathrm{Q}_{4}$ is fixed. Continuous fullbridge operation of the inverter in the $\left|v_{i n}\right|>v_{d c}$ region shown in Fig. 4(b) is possible if the minimum on-duty is set for $\mathrm{Q}_{2}$ and the on period is synchronized with $\mathrm{Q}_{3}$. By doing so, the inverter can output positive and negative voltages of amplitude $v_{d c}$. Continuous full-bridge operation of the inverter in the $\left|v_{i n}\right|<v_{d c}$ region shown in Fig. 4(c) is possible if the maximum on-duty is set for $\mathrm{Q}_{2}$ and the on period is synchronized for $\mathrm{Q}_{1}$ and $\mathrm{Q}_{4}$. By doing so, it is possible to control the DC link voltage and regulate the power while continuing full-bridge inverter operation by setting restrictions on the on-duty of switching device $\mathrm{Q}_{2}$ and performing PWM control, even in the state where it serves also as the boosting element of the $\mathrm{H}$-bridge PAM converter.

The pulse width of switching device $\mathrm{Q}_{2}$ is controlled based on the power factor correction control of the commercial input current and feedback control of the DC link voltage, and an inversion signal of $\mathrm{Q}_{2}$ is given as a drive signal of switching device $\mathrm{Q}_{1}$. The inverter can continue full-bridge operation by synchronizing a turn on timing of switching device $\mathrm{Q}_{2}$ with a turn on timing of switching device $\mathrm{Q}_{3}$. 


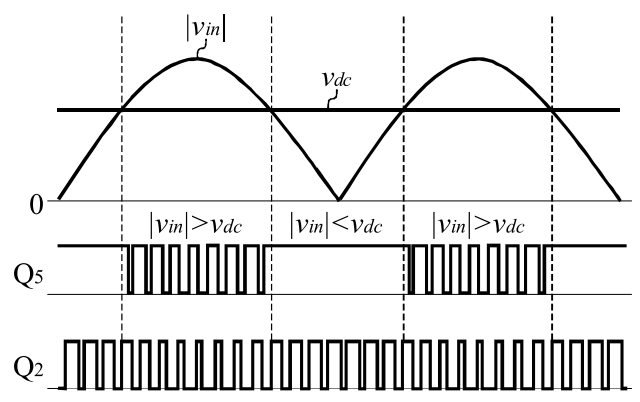

(a) H-bridge PAM Converter

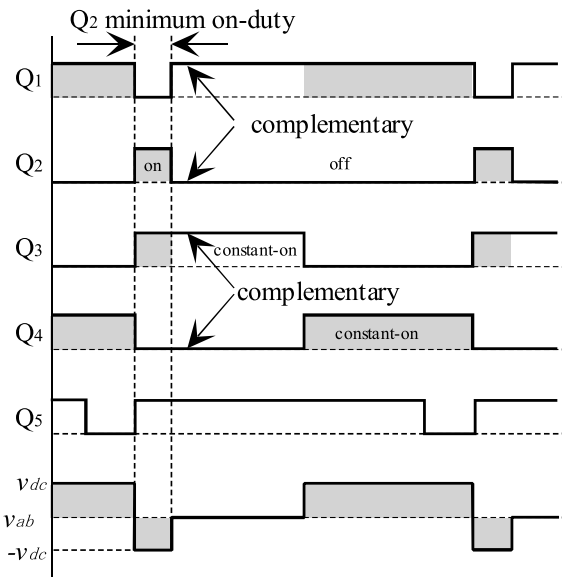

(b) high input voltage range; $\mid$ vin $\mid>$ vdc

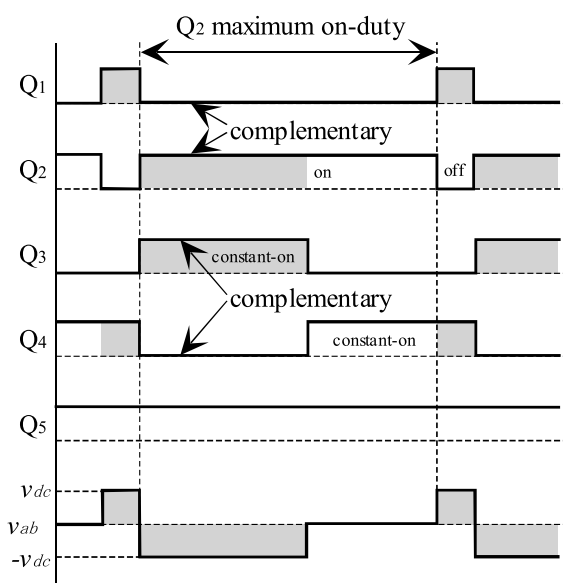

(c) low input voltage range; $\mid$ vin $\mid<$ vdc

Fig. 4. Operating waveforms of BBFB inverter when the pan is heated high-resistivity materials

\section{Verification by Prototype Tests}

\subsection{Design Specifications and Circuit Parameters}

We conducted tests to verify the effectiveness of the proposed BBFB inverter. The specifications and circuit parameters used in the testing are listed in Table 1. The number of work coil windings was 40 , the inverter switching frequency was $21.5 \mathrm{kHz}$ for iron cookware and about $90 \mathrm{kHz}$ for aluminum. For iron, magnetic stainless steel, and other highresistivity materials, resonant capacitor $\mathrm{C}_{\mathrm{r} 1}$ is set to $0.25 \mu \mathrm{F}$; for aluminum, copper, and other low-resistivity materials, resonant capacitor $\mathrm{C}_{\mathrm{r} 2}$ is set to $24.75 \mathrm{nF}$. $\mathrm{C}_{\mathrm{r} 2}$ has a withstand voltage of 2,300 VAC, and the withstand voltage and current capacity was ensured with a two-series, three-parallel configuration of $16.5 \mathrm{nF}$ film capacitors. Table 1 shows the
Table 1. Design specifications and circuit parameters

\begin{tabular}{|c|c|c|c|}
\hline \multicolumn{2}{|r|}{ Item } & Symbol & Value \\
\hline \multirow{2}{*}{\multicolumn{2}{|c|}{ Switching Device }} & $\mathrm{Q}_{1}, \mathrm{Q}_{2}$ & $\begin{array}{l}\text { IGBT Model } \\
\text { IRGP4062 }\end{array}$ \\
\hline & & $\mathrm{Q}_{3}-\mathrm{Q}_{5}$ & $\begin{array}{l}\text { IGBT Model } \\
\text { IRGP4068 }\end{array}$ \\
\hline \multicolumn{2}{|c|}{ Diode } & $\mathrm{D}_{5}$ & $\begin{array}{l}\text { FRD Model } \\
\text { KSF30A60B }\end{array}$ \\
\hline \multicolumn{2}{|c|}{ Filter Inductor } & Lf & $100 \mu \mathrm{H}$ \\
\hline \multicolumn{2}{|c|}{ Filter Capacitor } & $\mathrm{Cf}$ & $8 \mu \mathrm{F}$ \\
\hline \multicolumn{2}{|c|}{ Chopper Inductor } & L1 & $400 \mu \mathrm{H}$ \\
\hline \multicolumn{2}{|c|}{ DC Link Capacitor } & $\mathrm{Cdc}$ & $\begin{array}{c}1350 \mu \mathrm{F} \\
(450 \mu \mathrm{F} \times \\
3 \text { parallel })\end{array}$ \\
\hline \multicolumn{2}{|c|}{ Lossless Snubber Capacitor } & Cs3,Cs4 & $10 \mathrm{nF}$ \\
\hline \multicolumn{2}{|c|}{ Work Coil } & $\mathrm{Lr}$ & 40turn \\
\hline \multirow{4}{*}{$\begin{array}{c}\text { Work Coil } \\
\text { with metal pan }\end{array}$} & \multirow{2}{*}{$\begin{array}{l}\text { with Iron Pan } \\
\text { (at } 23 \mathrm{kHz} \text { ) }\end{array}$} & Ro & $7.96 \Omega$ \\
\hline & & Lo & $203 \mu \mathrm{H}$ \\
\hline & \multirow{2}{*}{$\begin{array}{l}\text { with Aluminum Pan } \\
\text { (at } 90 \mathrm{kHz} \text { ) }\end{array}$} & Ro & $1.02 \Omega$ \\
\hline & & Lo & $133 \mu \mathrm{H}$ \\
\hline \multirow[b]{2}{*}{$\begin{array}{l}\text { Resonant } \\
\text { Capacitor }\end{array}$} & with Iron Pan & $\mathrm{Cr} 1$ & $0.25 \mu \mathrm{F}$ \\
\hline & with Aluminum Pan & $\mathrm{Cr} 2$ & $\begin{array}{c}24.75 \mathrm{nF} \\
(16.5 \mathrm{nF} / 2 \text { series } \\
\times 3 \text { parallel })\end{array}$ \\
\hline
\end{tabular}

equivalent inductance $L_{o}$ and equivalent resistance $R_{o}$ with iron and aluminum pans on the work coil as reference values. Two-step aligned coil winding was used to obtain an outside diameter of $180 \mathrm{~mm}$ and a 40-turn winding. Litz wire, a conductor made of twisted fine wires, was used for the coil winding. The small diameter of the elemental wires and the twisting in Litz wire can suppress the increase in AC resistance caused by the skin effect and the proximity effect ${ }^{(15)}$. In the work reported here, we used an elemental wire diameter of $0.05 \mathrm{~mm}$ and a count of 1,200 wires.

3.2 Experiment Results Measured waveforms of Hbridge PAM Converter for when an aluminum pan is heated with $2.6 \mathrm{~kW}$ of power are presented in Fig. 5, where $v g_{2}$ and $v g_{5}$ are the gate driving voltages for switching devices $\mathrm{Q}_{2}$ and $\mathrm{Q}_{5}, i_{2}$ and $i_{5}$ are the collector currents for $\mathrm{Q}_{2}$ and $\mathrm{Q}_{5}$. The waveforms for the entire range of the commercial cycle are shown in Fig. 5(a), for the high input voltage region of $v_{\text {in }}$ in Fig. 5(b), and for the low input voltage region of $v_{\text {in }}$ in Fig. 5(c). As described above, when an aluminum pan is heated, the PAM converter and SEPP inverter operate independently. In the tests, the switching frequency of the PAM converter was set to about $30 \mathrm{kHz}$. From Fig. 5(a), the buck element $\mathrm{Q}_{5}$ switches between switching operation and the constantly-on state in each half of the cycle. On the other hand, the boost $\mathrm{Q}_{2}$ switches between switching operation and the constantly-off state in each half of the cycle.

Measured waveforms of the SEPP inverter for when an aluminum pan is heated with $2.6 \mathrm{~kW}$ of power are shown in Fig. 6, where $i_{3}$ is the collector current of $\mathrm{Q}_{3}$ and $i_{L}$ is the load current and $v_{b}$ is the output voltage of inverter. In the tests, the switching frequency of the SEPP inverter was set to about $90 \mathrm{kHz}$. From Fig. 6(a), the envelope curve of output voltage $v_{b}$ is the DC link voltage. For the load current $i_{L}$, 


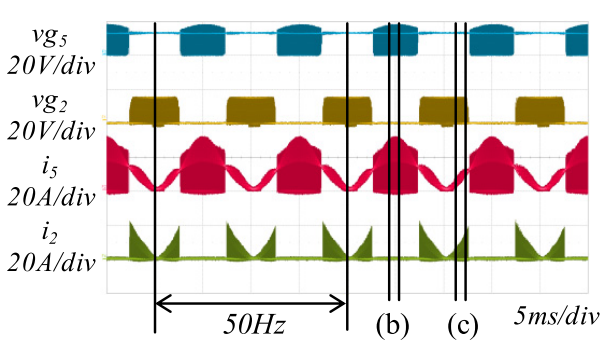

(a) all range

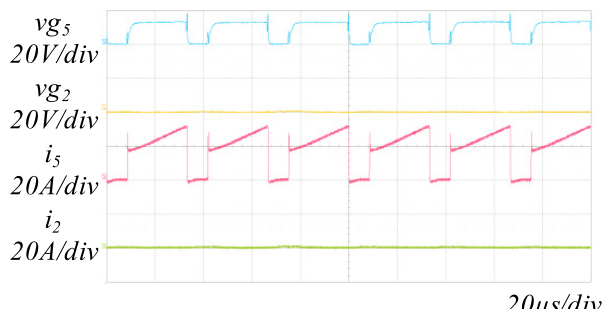

(b) high input voltage range

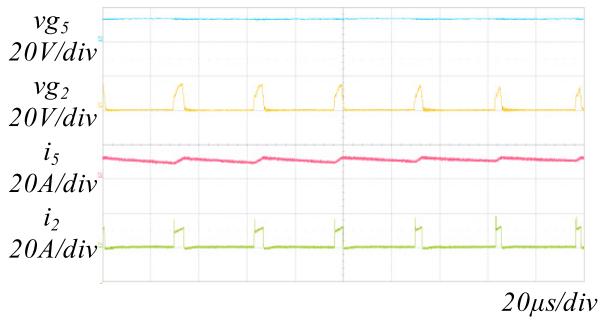

(c) low input voltage range

Fig. 5. Experimental waveforms of H-bridge PAM Converter when an aluminum pan is heated in $2.6 \mathrm{~kW}$ input
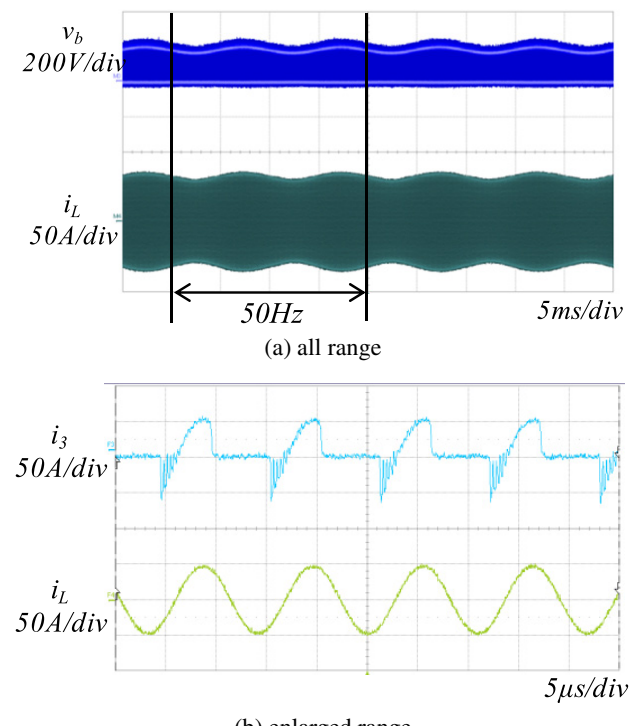

(b) enlarged range

Fig. 6. Experimental waveforms of SEPP Inverter when an aluminum pan is heated in $2.6 \mathrm{~kW}$ input

slight pulsing caused by the commercial cycle arises. From Fig. 6(b), the load current $i_{L}$ waveform is sinusoidal and that current resonance operation is normal because of the complementary operation of switching devices $\mathrm{Q}_{3}$ and $\mathrm{Q}_{4}$.

Various measured waveforms for when an iron pan is heated with $3 \mathrm{~kW}$ of power are presented in Fig. 7, where $v g_{1}, v g_{2}, v g_{3}$, and $v g_{5}$ are the respective gate driving voltages for switching devices $\mathrm{Q}_{1}, \mathrm{Q}_{2}, \mathrm{Q}_{3}$, and $\mathrm{Q}_{5}, i_{1}$ through $i_{3}$ are

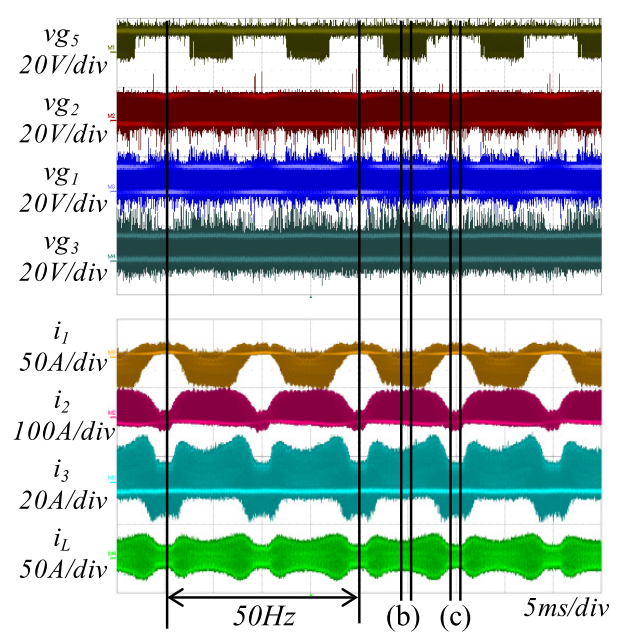

(a) all range

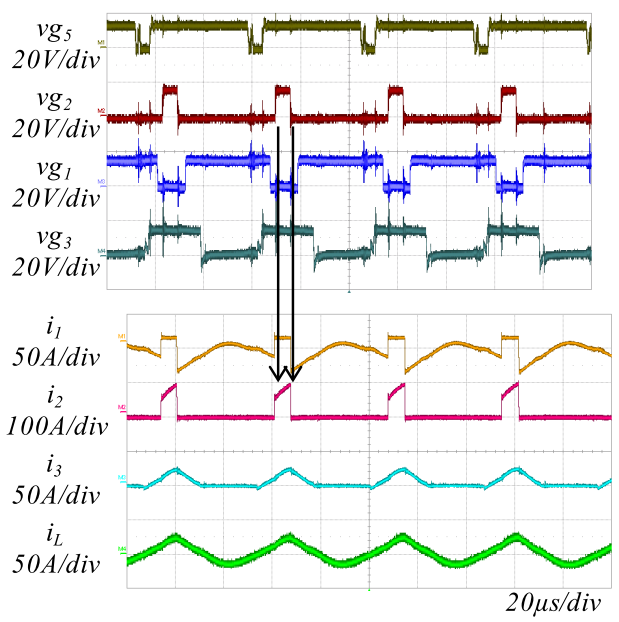

(b) high input voltage range

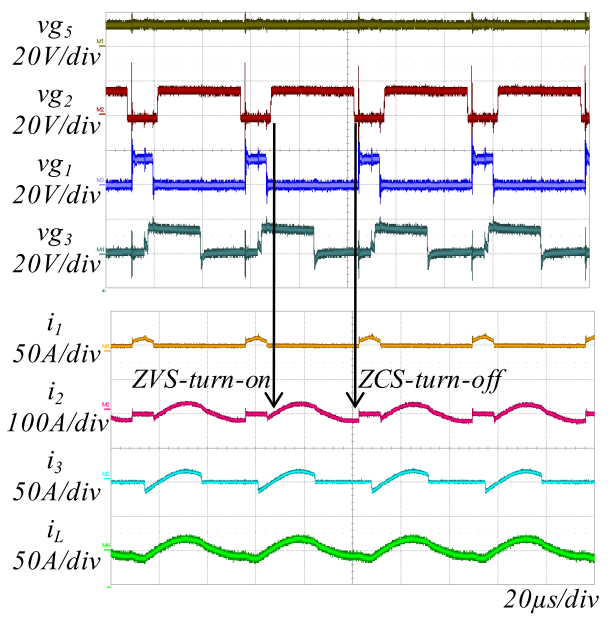

(c) low input voltage range

Fig. 7. Experimental waveforms when an iron pan is heated in $3 \mathrm{~kW}$ input

the respective collector currents for $\mathrm{Q}_{1}$ through $\mathrm{Q}_{3}$, and $i_{L}$ is the load current. The waveforms for the entire range of the commercial cycle are shown in Fig. 7(a), for the high input voltage region of $v_{\text {in }}$ in Fig. 7(b), and for the low input voltage region of $v_{i n}$ in Fig. 7(c). In the tests, the switching frequency was set to $21.5 \mathrm{kHz}$. We can see from Fig. 7(a), that the buck element $\mathrm{Q}_{5}$ switches between switching operation and the constantly-on state in each half of the cycle. We 
can see that $\mathrm{Q}_{2}$, on the other hand, is used as both a boosting element and an inverter element, and performs the switching operation in all regions. That is because, the on-duty of $\mathrm{Q}_{2}$ is restricted by a minimum value and a maximum value to maintain an interval in which $\mathrm{Q}_{2}$ and $\mathrm{Q}_{3}$, and $\mathrm{Q}_{1}$ and $\mathrm{Q}_{4}$ are on simultaneously for continuous inverter full-bridge operation as described above. For the load current $i_{L}$, a pulsing caused by the commercial cycle arises. That, as we can see from Figs. 7(b) and (c), is because the operation is such that power factor correction of the commercial input current is performed while the $\mathrm{Q}_{2}$ on time is $\mathrm{PWM}$ controlled according to the commercial input voltage. In the region of high commercial input voltage, as shown in Fig. 7(b), the $\mathrm{Q}_{2}$ on time is short, so the interval in which it is on at the same time as $\mathrm{Q}_{3}$ is also short and load current $i_{L}$ tends to decrease. Also, the chopper current is greater than the load current in this region, so $\mathrm{Q}_{2}$ is turned on by hard-switching. In the region of low commercial input voltage, as shown in Fig. 7(c), the on-time is long for $\mathrm{Q}_{2}$ but short for $\mathrm{Q}_{1}$. Thus, the interval in which $\mathrm{Q}_{1}$ and $\mathrm{Q}_{4}$ are on simultaneously is short and the load current $i_{L}$ tends to decrease in the same way as seen in Fig. 7(b). Also, the chopper current is less than the load current in this region, so the $\mathrm{Q}_{2}$ turn-on time is a zero-voltage switching (ZVS) operation and the operation is soft-switching to prevent switching loss. Furthermore, the polarity of the load current $i_{L}$ reverses in the interval when $\mathrm{Q}_{2}$ is on and current flows through the anti-parallel diode of $\mathrm{Q}_{2}$. Because the turnoff in that interval is by zero-current switching (ZCS) operation, switching loss does not occur. However, the chopper current and load current differ according to the control power, so soft-switching operation is not necessarily achieved in all power regions. In the method we propose, the condition for which the amplitude of load current $i_{L}$ is maximum is that the $\mathrm{Q}_{2}$ on-duty is near 0.5 .

Measured waveforms of the input voltage $v_{\text {in }}$ and the input current $i_{\text {in }}$ for when an iron pan is heated with a power of $3 \mathrm{~kW}$ are shown in Fig. 8. The input current $i_{\text {in }}$ is confirmed to be sinusoidal with a power factor of $99.5 \%$.

The power control characteristics for when an iron and aluminum pans are heated are shown in Fig. 9. In the proposed method, operation for power factor correction of the commercial input current and control of the input power with a variable DC link voltage $v_{d c}$ is achieved by performing PWM control of switching devices $\mathrm{Q}_{2}$ and $\mathrm{Q}_{5}$. That is to say, the input power is regulated by PAM control of the DC link voltage. For the inverter, the load characteristic can be regarded as a constant resistance because the switching frequency is fixed. Accordingly, the input power $\mathrm{P}_{\text {in }}$ can be confirmed as proportional to the square of the DC link voltage $v_{d c}$.

The power conversion efficiency from the commercial input to the output of inverter are shown in Fig. 10, when an iron and aluminum pans are heated. We see that the efficiency is flat over the wide range of input power from $0.5 \mathrm{~kW}$ to $3 \mathrm{~kW}$ when an iron pan is heated, confirming the effectiveness of the proposed method. In the case of aluminum pan heating, a conduction loss and switching loss increase because the load current is large. Therefore the power conversion efficiency is lower than iron pan heating.

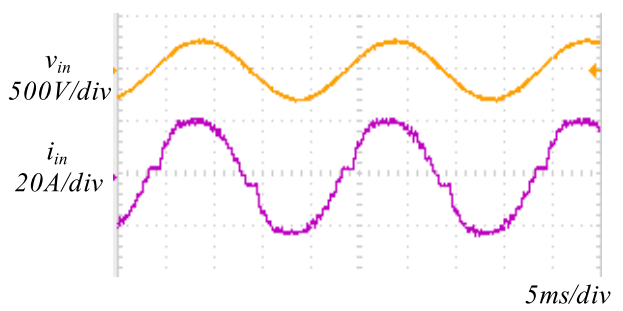

Fig. 8. Experimental waveforms when an iron pan is heated with $3 \mathrm{~kW}$ of power

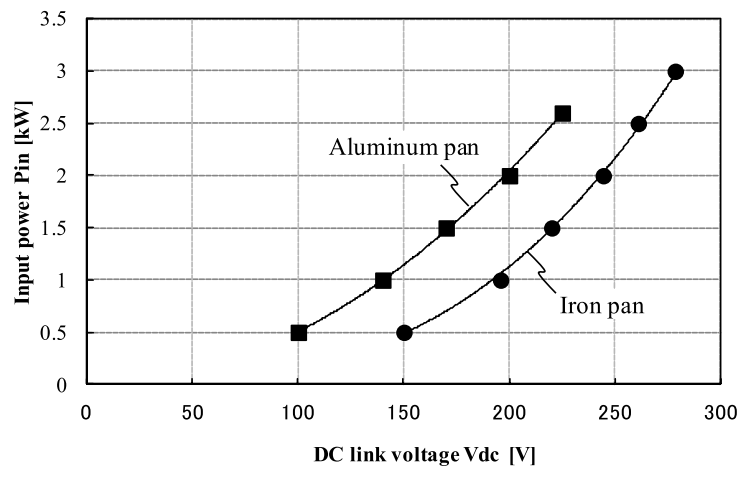

Fig. 9. Input power characteristics

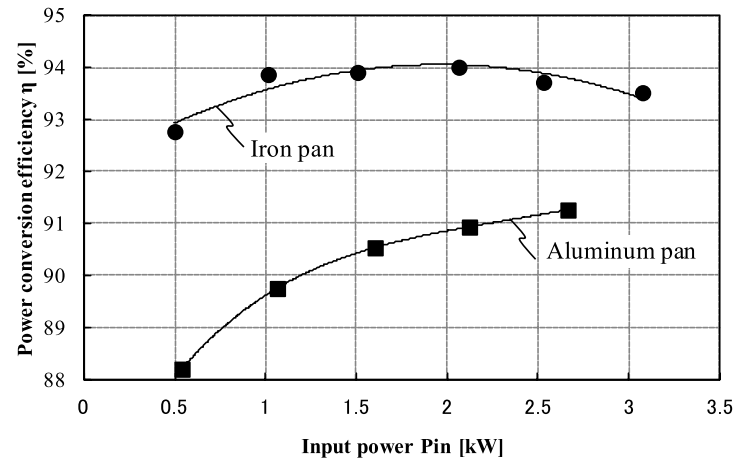

Fig. 10. Power conversion efficiency characteristics when iron pans

\section{Mounting Configuration}

A photograph showing the appearance of the printed circuit board with the proposed inverter mounted is shown in Fig. 11. The IGBT of the power semiconductors $Q_{1}$ through $\mathrm{Q}_{5}$, diode $\mathrm{D}_{5}$, and the diode bridges have aluminum fins attached for heat dissipation by cool air circulation. The chopper inductor $\mathrm{L}_{1}$, electrolytic capacitor $\mathrm{C}_{\mathrm{dc}}$, resonance capacitors $\mathrm{C}_{\mathrm{r} 1}$ and $\mathrm{C}_{\mathrm{r} 2}$, and relay $\mathrm{RY}_{1}$ are mounted on the same printed circuit board, which measures $205 \mathrm{~mm}$ by $280 \mathrm{~mm}$ and is $45 \mathrm{~mm}$ high.

A built-in type all-metals induction heating cookers equipped with the proposed inverter is shown in Fig. 12. Three heaters are arranged on the left, right and center of the flat top plate. The left and right heaters are all-metals heaters, which can heat cookware made of any metal, including aluminum and iron. The center heater can heat iron or stainless steel cookware. The induction heating cooker has an oven for cooking fish, poultry, pizza and other foods, so the space for installing the inverter is limited.

The installation configuration of the circuit boards is 


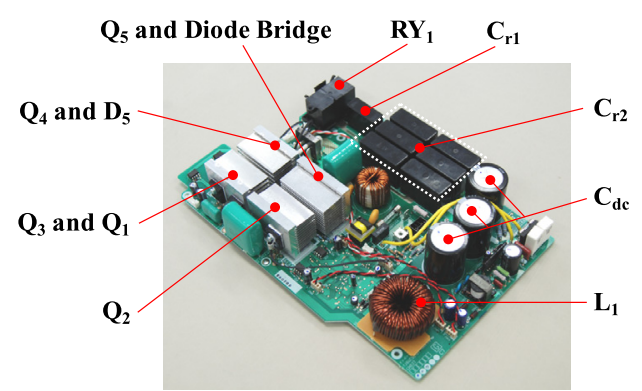

Fig. 11. Photograph of the printed circuit assembly

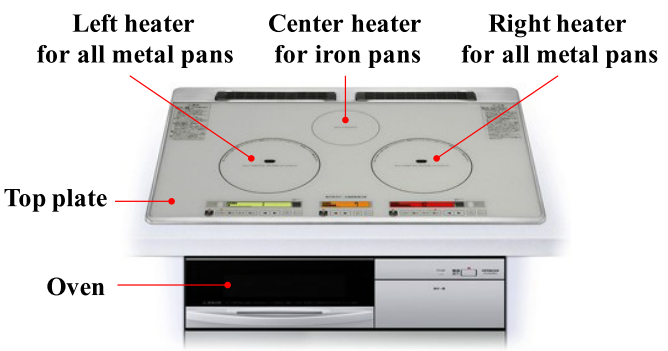

Fig. 12. The appearance of the all-metals induction heating cookers

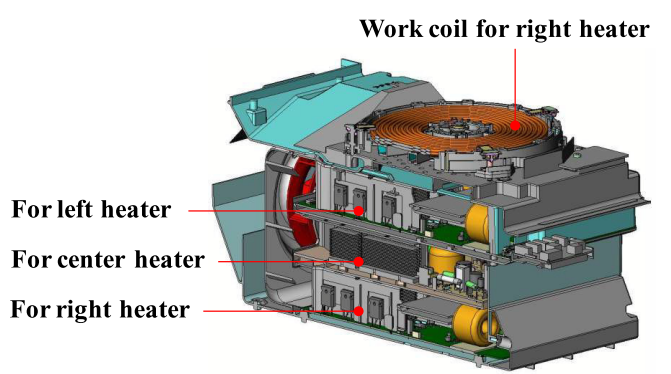

Fig. 13. Packaging structure of the printed circuit boards

shown in Fig. 13. The printed circuit board is installed in the empty space below the left heater, which is to say it is a high-density mounting in the small space next to the oven. The boards are installed in three layers, with the board for the right heater on the bottom and the boards for the center and left heaters placed above it in order.

\section{Conclusion}

We have proposed a BBFB inverter that serves as both an H-bridge PAM converter and part of a full-bridge inverter power device and described the circuit configuration and power control method. We also presented the results of verification tests and described an actual installation configuration. The BBFB inverter can be switched between a configuration for use as a converter and part of an inverter power device when heating high-resistivity iron cookware, and for independent operation as a converter and an inverter when heating low-resistivity aluminum cookware.

Tests confirmed that input power can be controlled by power factor correction of the input current and PAM control of the DC link voltage when heating iron cookware. The power conversion efficiency exhibits a roughly flat characteristic over the wide range of input power from $0.5 \mathrm{~kW}$ to $3 \mathrm{~kW}$, which confirms the effectiveness of the proposed method when applied to induction heating cookers. We confirmed that, when heating aluminum cookware, the H-bridge converter and SEPP inverter are made to operate independently, so the inverter maintains low-loss soft-switching operation and the converter can perform power factor correction and PAM control DC link voltage for power control, even under low-resistivity load conditions in which there are sharp changes in the frequency characteristics.

We implemented the proposed method as left and right induction heaters in an all-metals induction heating cooker.

\section{References}

( 1 ) Special Investigative Committee on High-frequency Resonant Circuits: "Latest Trend in Soft Switching Technology", IEEJ Tech. Report, No.899 (2002) (in Japanese)

( 2 ) H. Oomori and I. Hirota: "Power Electronics Changes Home Appliances", $T$. IEE Japan, Vol.119-D, No.2, pp.127-132 (1999) (in Japanese)

( 3 ) H. Sugimura, L. Gamage, H. Muraoka, K. Soushin, and M. Nakaoka: "Dual Mode Control Soft Switching High Frequency Inverter", TECHNICAL REPORT OF IEICE, EE2003-10, pp.55-60 (2003-05) (in Japanese)

( 4 ) H. Ogiwara, M. Itoi, and M. Nakaoka: "SEPP-ZVS High Frequency Inverter Incorporating Auxiliary Switch", T. IEE Japan, Vol.123-D, No.10, pp.12361237 (2003) (in Japanese)

( 5 ) H. Ogiwara and M. Nakaoka: "Soft Switching SEPP High Frequency Inverter for Induction Heating", T. IEE Japan, Vol.124-D, No.5, pp.523-524 (2004) (in Japanese)

( 6 ) Y. Kurose, A. Okuno, E. Hiraki, and M. Nakaoka: "Phase Shifted ZVSPWM High Frequency Load Resonant Inverter with Active Auxiliary Resonant Switching Block and It's Application", Technical Report of IEICE, EE2002-31, pp.1-5 (2002) (in Japanese)

( 7 ) Y.L. Feng and M. Nakaoka: "Zero Current Soft-Switching High Frequency Inverter with PDM Control Scheme for Induction Heating Roller", T. IEE Japan, Vol.123-D, No.2, pp.112-120 (2003) (in Japanese)

( 8 ) H. Shoji, J. Uruno, and M. Isogai: "Bypass Type ZVS-PWM High Frequency Inverter for Induction Heating", T. IEE Japan, Vol.130-D, No.12, pp.13491355 (2010) (in Japanese)

( 9 ) H. Sadakata, A. Fujita, S. Sumiyoshi, H. Omori, B. Saha, T. Ahmed, and M. Nakaoka: "Latest Practical Developments of Triplex Series Load Resonant Frequency-Operated High Frequency Inverter for Induction-Heated Low Resistivity Metallic Appliances in Consumer Built-In Cooktops", APEC, pp.1825-1832 (2010)

(10) J. Uruno, H. Shoji, Y. Kaminaga, and M. Isogai: "The Power Supply Change typ Induction-Heating System corresponding to heated thing made from aluminum”, Proc. The Japan Industry Applications Society Conference, Vol.1, pp.117-118 (2005) (in Japanese)

(11) H. Shoji, J. Uruno, and M. Isogai: "Induction Heating System for All Types of Metal Pans Employing a Method of Changing the DC Link Voltage and the Number of Turns of the Work Coil", T. IEE Japan, Vol.133-D, No.11, pp.1082-1088 (2013) (in Japanese)

(12) J. Uruno, H. Shoji, Y. Kaminaga, and M. Isogai: "The all metal inductionheating system using an inverter change system", Proc. The Japan Industry Applications Society Conference, Vol.1, pp.303-304 (2006) (in Japanese)

(13) J. Uruno, H. Shoji, T. Okubo, and M. Isogai: "Studies of the PulseAmplitude-Modulation converter which can improve power factor suitable for Induction Heating", Proc. The Japan Industry Applications Society Conference, Vol.1, pp.467-470 (2009) (in Japanese)

(14) H. Shoji, J. Uruno, and M. Isogai: "Buck-Boost-Full-Bridge Inverter for AllMetal Induction-Heating Cookers", Proc. The Japan Industry Applications Society Conference, Vol.1, pp.513-516 (2011) (in Japanese)

(15) T. Mizuno, A. Kamiya, Y. Simura, K. Iida, D. Yamamoto, N. Miyao, and H. Sasadaira: "Consideration on Influences of Number of Strands on AC Resistance of Litz Wire", Proc. The Japan Society Applied Electromagnetics and Mechanics, Vol.18, No.3, pp.124-129 (2010) (in Japanese) 
Hiroyuki Shoji (Member) received the bachelor's degree in electrical

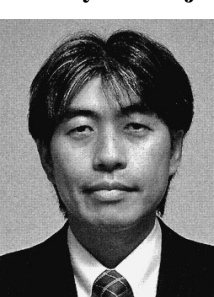
engineering from Yamagata University, Yamagata, Japan, in 1995. In 2014, he enrolled in the Graduate School of Ibaraki University, Ibaraki, Japan, and is currently working toward the doctoral degree. Since 1995, he has been with Hitachi Research Laboratory, Hitachi Ltd., His research interests include power electronics and resonant converter in particular. He is currently a Senior Researcher in the Research \& Development Group. He was the recipient of the 2015

IEEJ Distinguished Paper Award.

Junpei Uruno (Member) graduated from the Ibaragi Prefectural Mito Technical High School in Ibaragi, Japan in 1990 and joined the Hitachi Research Laboratories in the same year. He is engaged in research on power electronics, and switching power converters in particular. He is a professional engineer of the Electrical \& Electronics Engineering. He was the recipient of the 2015 IEEJ Distinguished Paper Award.
Masayuki Isogai (Non-member) received the bachelor's degree in

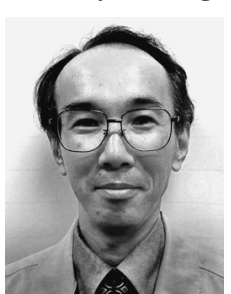
electrical engineering from the Shibaura Institute of Technology in 1986 and joined Hitachi Heating Appliances, Inc. in the same year. He is currently designing electronic circuits for home electronics in the Home Electronics department of Hitachi Appliances, Inc. He was the recipient of the 2015 IEEJ Distinguished Paper Award.

Takeshi Yanagidaira (Member) received the bachelor's degree in

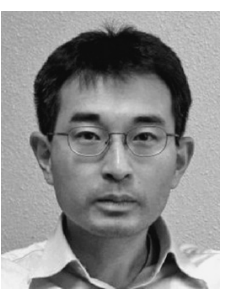

electrical and electronics engineering from Gunma University in 1993. He completed the doctoral program in electronics and information engineering at Gunma University in 1998. He took the position of Assistant in the Engineering Department of Ibaragi University in April, 2000 and is currently serving as Professor in the Department of Electrical and Electronic Engineering. He is researching applications to semiconductor-based pulse power generation circuits and water treatment, agricultural applications, and other applications. He is a member of the Plasma Fusion Technical Society. 